\title{
Effects of Pre-Corrosion on the Corrosion Inhibition Performance of Three Inhibitors on Q235 Steel in $\mathrm{CO}_{2} / \mathrm{H}_{2} \mathrm{~S}$ Saturated Brine Solution
}

\author{
Chen Zhang ${ }^{1}$, Jingmao Zhao ${ }^{1,2, *}$ \\ ${ }^{1}$ College of Material Science and Engineering, Beijing University of Chemical Technology, Beijing \\ 100029, China \\ ${ }^{2}$ Beijing Key Laboratory of Electrochemical Process and Technology for Materials, Beijing 100029, \\ China \\ *E-mail: jingmaozhao@126.com
}

doi: $10.20964 / 2017.10 .51$

Received: 8 June 2017 / Accepted: 7 August 2017 / Published: 12 September 2017

\begin{abstract}
Effects of pre-corrosion on the corrosion inhibition performance of three inhibitors on Q235 steel in a $\mathrm{CO}_{2} / \mathrm{H}_{2} \mathrm{~S}$ saturated brine solution were investigated with potentiodynamic polarization, electrochemical impedance spectroscopy (EIS), scanning electron microscope (SEM), X-ray diffraction (XRD), energy dispersive spectrometer (EDS), and X-ray photoelectron spectroscopy (XPS). The results showed that the corrosion rate of steels was decreased significantly after precorrosion for different times indicating a good protection effect of the pre-corrosion products, which were composed of mostly $\mathrm{FeS}$ and limited $\mathrm{FeCO}_{3}$. The inhibitors could both inhibit the $\mathrm{CO}_{2} / \mathrm{H}_{2} \mathrm{~S}$ corrosion of freshly abraded Q235 steels and the pre-corroded ones, but the pre-corrosion could gradually deteriorate their inhibition performances with the increase of pre-corrosion time. And the difference in their inhibition performances became relative distinct after pre-corrosion for 7 days possibly due to the differences of their molecular structures. According to the XPS results, the inhibitor films could be formed on the surface of the corrosion product layer. However, the corrosion species might be also diffused to the steel surface through the diffusion channels in the corrosion products and attack the steel matrix.
\end{abstract}

Keywords: Tetradecyl trimethyl ammonium bromide; N-benzyl pyridinium chloride; Imidazoline quaternary ammonium salt; Pre-corrosion; Acid corrosion

\section{FULL TEXT}

(C) 2017 The Authors. Published by ESG (www.electrochemsci.org). This article is an open access article distributed under the terms and conditions of the Creative Commons Attribution license (http://creativecommons.org/licenses/by/4.0/). 